Running Head: Determinants of Job Crafting

\title{
Psychological and Relational Conditions for Job Crafting to Occur
}

Tiphaine Huyghebaert-Zouaghi ${ }^{\mathrm{a} *}$, Sophie Berjot ${ }^{\mathrm{a}},{\text { Baptiste } \text { Cougot }^{\mathrm{b}}, \& \text { Nicolas Gillet }}^{\mathrm{c}}$

${ }^{a}$ Université de Reims Champagne Ardenne, France (E.A. 6291 Laboratoire C2S)

${ }^{\mathrm{b}}$ Université de Tours, France (E.E. 1901 QualiPsy)

${ }^{\mathrm{c}}$ Institut Universitaire de France (IUF)

\section{Corresponding author :}

Tiphaine Huyghebaert-Zouaghi

Université de Reims

Laboratoire C2S (E.A. 6291)

UFR Lettres et Sciences Humaines, Département de Psychologie

57 rue Pierre Taittinger, 51100 Reims, France

tiphaine.huyghebaert@univ-reims.fr

This is the postprint version of the following article :

Huyghebaert-Zouaghi, T., Berjot, S., Cougot, B., \& Gillet, N. (2020). Psychological and relational conditions for job crafting to occur. Stress and Health. Advance online publication. https://doi.org/10.1002/smi.3014

This article has been accepted for publication and undergone full peer review, but has not been through the copyediting, typesetting, pagination, and proofreading process, which may lead to differences between this version and the Version of Record.

This article is protected by copyright. All rights reserved. 


\begin{abstract}
This study aimed to provide a wider understanding of the determinants of job crafting by jointly considering employee well- and ill-being (work engagement and exhaustion) and socio-environmental factors (supervisor and colleague support) as possible levers to promote job crafting. A secondary goal of this research was to simultaneously explore the multidimensionality of work engagement and the potentially differentiated associations between the different facets of work engagement and job crafting behaviors. Questionnaire surveys were collected among 533 workers from various organizations located in France. Results from preliminary analyses showed the superiority of a Bifactor Exploratory Structural Equation Modeling (B-ESEM) representation of work engagement when compared to alternative representations of ratings of this multidimensional construct. Specifically, employees' ratings of work engagement simultaneously reflected a global work engagement construct, which co-existed with specific vigor, dedication, and absorption components. Results from a predictive model indicated that the different facets of work engagement held differentiated relations with job crafting behaviors, while exhaustion did not significantly relate to any job crafting behaviors. Colleague and supervisor support also held differentiated relations with the demands-related job crafting behaviors, while both forms of support were associated with employees' seeking more job resources. Theoretical and practical implications are discussed.

Keywords: Work engagement; exhaustion; supervisor support; colleague support; job crafting; bifactor exploratory structural equation modeling.
\end{abstract}


Exploring today's dynamic work environments, research has shown that there was a limit to the sole consideration of the traditional top-down perspective of job design. This perspective posits that workers' job demands and resources are designed for them by higherranking people in the organization (e.g., managers, human resources directors) and that, in turn, employees experience well- or ill-being (Bakker \& Demerouti, 2017). Precisely, authors have argued that, if employees were just reactive to the job demands and resources that their organization designed for them, there would be no such variety of working conditions for individuals in a same job, and therefore suggested that employees can proactively change the characteristics of their job (Tims \& Bakker, 2010; Wrzesniewski \& Dutton, 2001). This complementary bottom-up approach of job design came with the identification of job crafting as a distinct form of proactive work behaviors.

Job crafting was originally conceptualized by Wrzesniewski and Dutton (2001) who suggested that employees may try to craft their jobs by altering task-related aspects of their job (e.g., the amount or content of their job tasks), by modifying relational aspects of their job (e.g., spending time with inspiring co-workers), and by changing their own cognitions about their job (e.g., thinking of certain aspects of their job in a more positive manner). Several researchers offered alternative definitions of job crafting, yet the most widely adopted conceptualization is the one proposed by Tims and Bakker (2010), suggesting that employees may engage in four different forms of job crafting behaviors : Increasing their challenging job demands (e.g., taking on a new project), decreasing the hindering demands of their jobs (e.g., reducing red tape), increasing social job resources (e.g., seeking social support), and increasing the structural resources of their job (e.g., trying to develop their skills). Based on evidence from factor analyses, these last two dimensions (increasing structural and social job resources) were merged into one increasing job resources factor (Petrou, Demerouti, Peeters, Schaufeli, \& Hetland, 2012), thus differentiating between three types of job crafting (i.e., 
increasing job resources, increasing challenging job demands, and reducing hindering job demands). We relied on this three-factor model in the present research.

Because job crafting appears like a promising alternative in a context where there is little leverage for traditional job re-design approaches, over the past decade, research has explored its antecedents, in order to promote it. Specifically, as pointed by a recent meta-analysis (Rudolph, Katz, Lavigne, \& Zacher, 2017), the determinants of job crafting can be classified into three categories: Individual differences (e.g., personality), job characteristics (e.g., autonomy), and demographics (e.g., tenure). The fact that this meta-analysis does not include employees' psychological health as a possible determinant of job crafting illustrates how little attention past research has paid to employees' health as a condition for job crafting to occur. However, the Job Demands-Resources (JD-R) model proposes that job crafting stems from employees' well-being, so that engaged employees are motivated to remain in this state of well-being and thus more prone to engage in job crafting behaviors to create their own gain spiral of resources (Bakker \& Demerouti, 2017). Conversely, exhausted employees may try to preserve themselves from further resource loss (Hobfoll, 2001) and thus not engage in effortful job crafting behaviors. As such, exhaustion may fuel a loss cycle of selfundermining.

Yet, to the best of our knowledge, research has provided little empirical support for these theoretical propositions. Moreover, prior research has scarcely considered these indicators jointly and their relation to job crafting (Hakanen, Peeters, \& Schaufeli, 2018). However, considering both these outcomes is of particular importance as they cover both positive and negative aspects of workers' functioning, which are both necessary to allow for a more complete and balanced understanding of psychological health (Keyes, 2005). Therefore, the present research will further explore the links between well- (work engagement) and ill-being (exhaustion) and job crafting. Precisely, we will offer a first examination of how the different 
facets of work engagement associate with distinct job crafting behaviors, which prior research has failed to explore.

This research will also consider colleague and supervisor support as possible antecedents of job crafting. To this day, the literature remains scarce on the socio-environmental conditions that may allow for job crafting to occur (e.g., Mäkikangas, Bakker, \& Schaufeli, 2017). However, it is essential to uncover such contextual factors in order to offer organizations leverage to promote job crafting. Indeed, many studies have pointed to individual differences and demographics (see Rudolph et al., 2017) as determinants of job crafting. Yet, organizations have little leeway to act on such factors, while they could have more flexibility to develop colleague and supervisor support if they proved to be relevant determinants of job crafting. The present research will thus explore whether such socioenvironmental conditions may promote job crafting, while jointly considering employees' psychological health as a determinant of job crafting.

It should be noted that most of the research on the psychological and relational determinants of job crafting has been conducted in the Netherlands or in Scandinavian countries (e.g., Hakanen et al., 2018; Hetland, Hetland, Bakker, \& Demerouti, 2018; Mäkikangas et al., 2017; Petrou, Demerouti, \& Schaufeli, 2015; Thun \& Bakker, 2018), and often times in samples of workers from specific occupations (e.g., police officers, dentists, knowledge workers, healthcare professionals: Hakanen et al., 2018; Hetland et al., 2018; Mäkikangas et al., 2017; Petrou et al., 2015). Because of this focus on specific occupations and countries (see Lichtenthaler \& Fischbach, 2019, for a review) one may wonder about the psychological and relational determinants of job crafting in occupations and countries where this construct was less studied. Indeed, recent research suggested that job crafting may not be as beneficial for employees in some countries and occupations as it is in others, and suggested that, for employees to fully benefit from such proactive redesign strategies, policy makers and 
organizations should first create the conditions for job crafting to occur (HuyghebaertZouaghi, Morin, Forest, Fouquereau, \& Gillet, 2020). As such, the present research will examine the psychological and relational determinants of job crafting in a country where job crafting has very rarely been explored (i.e., France) in a sample of workers from various occupations.

\section{Being in Good Psychological Health: A Prerequisite to Engage in Job Crafting?}

According to Petrou et al. (2012), employees engage in job crafting strategies in order to make their job healthier. Logically, job crafting research has largely addressed the relationships between job crafting and psychological health. On one hand, researchers showed that employees who craft their jobs create an enriched and challenging work environment that promotes growth and learning for themselves, and therefore experience increased well-being (see Schuler, Binnewies, \& Bürkner, 2019). On the other hand, studies showed that workers who engage in job crafting create more resources for themselves to better achieve their work tasks and regulate the demands that may drain their energy, and therefore are less prone to illbeing (e.g., Tims, Bakker, \& Derks, 2013). Although job crafting promotes employees' psychological health at work, one may wonder whether employees' psychological health conditions their ability to engage in job crafting in the first place.

A few studies have pursued this avenue and found contrasted results depending on job crafting dimensions. For instance, Tims, Bakker, and Derks (2015) showed that employees' work engagement predicted more seeking resources and challenging demands one month later, yet it did not significantly predict reducing hindering demands. Hakanen et al. (2018) also found work engagement to predict more seeking resources and challenging demands four years later, and, though to a lesser extent, less reducing of hindering demands. Conversely, exhaustion was found to predict increased levels of reducing hindering demands and a decrease in seeking resources, but it did not significantly predict seeking challenging job 
demands (Hakanen et al., 2018). Finally, exhaustion was associated with an increase in reducing hindering demands one year later, but it did not significantly predict seeking resources and challenging demands dimensions (Petrou et al., 2015).

In sum, though there are some contrasting results which may be due to the use of different time lags in prior studies, research still emphasizes some consensual conclusions: Engaged employees are more prone to seek job resources and challenging demands, and exhausted employees are more likely to reduce the hindering demands of their jobs. In other words, as further demonstrated by a meta-analysis (Lichtenthaler \& Fischbach, 2019), work engagement positively predicts promotion-focused forms of job crafting (i.e., employees try to add to their jobs and maximize their gains; increasing job resources and challenging job demands), while exhaustion positively predicts prevention-focused forms of job crafting (i.e., employees attenuate some aspects of their jobs in order to avoid losses or pain; decreasing hindering demands).

These differentiated findings may be interpreted in light of Hobfoll's (2002) conservation of resources (COR) theory which posits that individuals have a natural drive to obtain, retain, foster and protect their resources. Resources are defined as "those entities that either are centrally valued in their own right, or act as means to obtain centrally valued ends" (Hobfoll, 2002, p. 307). Precisely, this theory suggests that the way individuals accumulate their resources determines their behaviors. In other words, employees who feel vigorous, dedicated, and absorbed in their job (i.e., work engagement; Schaufeli, Bakker, \& Salanova, 2006), because they feel very resourceful, are more inclined to seek resources and challenging demands as they allow them to maintain or even foster this positive state. Conversely, employees who feel like their resources are depleted and experience intense fatigue (i.e., exhaustion; Schaufeli, Leiter, Maslach, \& Jackson, 1996) may lack the energy to invest their limited resources in such promotion-focused job crafting behaviors, as such behaviors may be 
seen as a risk to drain the scarce resources they have left. However, exhausted employees may try to protect themselves from further resource loss by reducing the hindering demands of their jobs (i.e., prevention-focused job crafting). Therefore, employees' work engagement and exhaustion seem to constitute key determinants of job crafting behaviors.

Yet, solely one study has jointly considered how both these indicators of psychological health relate to employees' job crafting (Hakanen et al., 2018) and did so in a specific population of Finnish dentists. Authors therefore called for further investigations of these relationships in order to verify their generalizability to other occupational groups. Therefore, our research offers to address this call by exploring how work engagement and burnout relate to job crafting in a diversified sample of workers, from a different culture.

\section{The Facets of Work Engagement and Job Crafting}

One may wonder how the different facets of work engagement (vigor, dedication, absorption) relate to specific job crafting strategies. However, existing research on the relation between work engagement and job crafting (Hakanen et al., 2018; Tims et al., 2015) has failed to explore how the different facets of work engagement relate to employees' job crafting behaviors. Yet, it would be informative to understand whether specific aspects of work engagement are more critical than others in promoting different job crafting strategies. In other words, it would be fruitful to understand whether the distinct dimensions of work engagement have differentiated associations with job crafting behaviors, which the present research will offer to explore.

Precisely, we built upon recent research on the dimensionality of work engagement, which revealed that work engagement ratings could be represented in a way that made it possible to simultaneously consider two complementary components (Gillet et al., 2019; Perera, Vosicka, Granziera, \& McIlveen, 2018): A first component reflecting employees' global levels of work engagement across all three dimensions, and a second component reflecting the more specific 
levels of vigor, dedication, and absorption left unexplained by the global level of work engagement. This improved psychometric representation of the multidimensionality of work engagement thus allows to clearly identify the unique contribution of each dimension over and above that of global levels (Gillet et al., 2019; Perera et al., 2018). Our research therefore offered a first exploration of how work engagement's global and specific factors relate to different job crafting behaviors.

Although job crafting is also a multidimensional construct, we did not resort to such psychometric representation of its multidimensionality because, unlike work engagement's facets, job crafting dimensions are often examined as independent variables in the literature (e.g., Hakanen et al., 2018; Petrou et al., 2015; Tims et al., 2015). Moreover, a meta-analysis recently indicated that the distinct job crafting behaviors may not be best reflected by a global job crafting component encompassing all dimensions (Rudolph et al., 2017). As such, and because there is no evidence in the literature to support such a psychometric representation of job crafting, we decided to resort to a more traditional modeling of the facets of job crafting. ${ }^{1}$

Because there is no evidence in the existing research to suggest independent relations between the distinct facets of work engagement and different job crafting behaviors, we could not formulate any specific hypothesis with regards to these specific relationships. We thus left as an open question whether work engagement's global and specific factors hold differentiated relations with job crafting strategies. Moreover, given that prior research seems to lack consensus when it comes to the relationship between work engagement and reducing hindering demands (e.g., Hakanen et al., 2018; Tims et al., 2015) and the association between

\footnotetext{
${ }^{1}$ However, for exploratory purposes, in line with recent research on the multidimensionality of work engagement, we did explore whether job crafting ratings could be represented in a way that made it possible to simultaneously consider global levels of job crafting together with non-redundant specific levels of seeking job resources, seeking challenging job demands, and reducing hindering job demands. Results indicated that this representation of job crafting was not able to achieve an acceptable level of fit to the data, thus corroborating our suggestion that a bifactor representation of job crafting may not be the most appropriate. Detailed results are available upon request from the authors.
} 
exhaustion and seeking resources and challenging demands (Hakanen et al., 201; Petrou et al., 2015), we could not draw specific hypotheses pertaining to these relationships. Therefore, we left as an open question whether work engagement would significantly relate to reducing hindering demands and whether exhaustion would significantly associate with seeking job resources and challenging demands. Nevertheless, based on prior findings, we propose the two following hypotheses.

Hypothesis 1: Work engagement positively relates to seeking job resources and challenging demands.

Hypothesis 2: Exhaustion positively relates to reducing hindering demands.

Although prior research does not allow us to formulate specific hypotheses pertaining to the relations between work engagement and prevention-focused forms of job crafting (i.e., reducing hindering demands) on one hand, and between exhaustion and promotion-focused forms of job crafting (i.e., seeking resources and challenging demands) on the other hand, COR theory may offer some preliminary answers. Could engaged workers be less likely to reduce the hindering demands of their jobs, as they have the necessary resources to cope with these hindering demands? Conversely, could exhausted workers be less likely to engage in promotion-focused forms of job crafting (i.e., seeking resources and challenging demands) which are resource-consuming, as they have limited resources and want to avoid further resource loss? Our research will attempt to answer these research questions.

In their joint examination of work engagement and exhaustion, Hakanen et al. (2018) solely considered these indicators of psychological health as predictors of job crafting. Yet, research has showed that socio-environmental factors may play an important part in creating the conditions for job crafting to occur (e.g., Mäkikangas et al., 2017). Therefore, our research offers to build upon prior research by jointly considering individuals' psychological health 
(work engagement and exhaustion) and socio-environmental conditions (supervisor and colleague support) as sources of job crafting.

\section{Do Supportive Colleagues and Supervisors Create a Fertile Ground for Job Crafting?}

When it comes to considering the socio-environmental conditions that may allow for job crafting to occur, it is crucial to consider employees' relational environment. Because tasks and people are highly interdependent at work, job crafting has important interpersonal implications (Tims \& Parker, 2020). In other words, there are relational issues at stake when engaging in job crafting, and those issues may encourage or refrain workers from engaging in such strategies.

In their qualitative research, Berg, Grant, and Johnson (2010) found colleague support to be one of the most cited prerequisite for employees to craft their job. When they modify their job, employees may affect their colleagues' tasks and interactions. It is thus critical that they feel supported by their colleagues before engaging in job crafting behaviors that may impact them. Indeed, individuals fundamentally need to feel related to others and often refrain from engaging in behaviors that may threaten their sense of connectedness (Baumeister \& Leary, 1995). Therefore, it appears decisive that employees perceive their peers as supportive of their job crafting strategies before engaging in such behaviors.

However, few studies have further explored this idea that employees' job crafting may depend on the social support provided by their coworkers. For instance, researchers found social support to positively predict employees' crafting for social job resources three months later (Kerksieck, Bauer, \& Brauchli, 2019). Yet, this study only explored one facet of the seeking resources strategy (i.e., social job resources), thus omitting employees' seeking structural job resources and challenging demands, and their reducing hindering job demands. Audenaert et al. (2020) did explore all these facets of job crafting in their cross-sectional study conducted in public organizations. Authors found that the more employees perceived 
social support from their coworkers, the more they engaged in seeking job resources and challenging job demands. However, social support from colleagues did not significantly relate to employees' reducing of their hindering job demands.

Evidence from prior research therefore seems to suggest that colleague support helps employees seize the opportunity to seek more job resources and challenging demands. Because social support is a valued psychosocial resource and because individuals have a natural tendency to obtain and foster their resources and thus create resource caravans (Hobfoll, 2011), it appears that colleague support may help employees create their own gain spiral of resources. When it comes to the relationship between colleague support and employees' reducing of hindering demands, the above mentioned research evidence does not allow to draw specific hypotheses. One may argue that when employees feel supported by their colleagues, they do not fear negative interpersonal consequences for their behaviors and thus feel free to reduce the hindering demands of their job. Others could posit that, when they feel supported by their coworkers, employees feel obligated to return this positive treatment by taking on hindering job demands so that others do not carry these burdening demands by themselves (Blau, 1964). Therefore, we left as an open question whether colleague support would positively or negatively relate to employees' reducing hindering job demands.

\section{Hypothesis 3: Colleague support positively relates to seeking job resources and} challenging job demands.

Not only can colleagues constitute a more or less fertile ground for job crafting to occur, but so can leaders. A few studies showed that leaders could stimulate employees' job crafting. For instance, a research demonstrated that supervisor autonomy support (i.e., supporting employees' interests and encouraging their initiative and decision-making) was positively related to overall job crafting (Slemp, Kern, \& Vella-Brodrick, 2015). Similarly, Mäkikangas et al. (2017) showed that engaging leadership (i.e., leaders who inspire, strengthen, and 
connect their followers) was positively associated with employees' overall job crafting. Transformational leaders, because they inspire towards constant change and encourage selfmanagement, also trigger job crafting strategies in the form of seeking resources (Hetland et al., 2018). However, transformational leadership does not appear to significantly relate to the seeking of challenging demands, which, authors argue, may be because transformational leaders challenge their followers sufficiently in the first place, so that they do not feel a need to further try to increase the challenging demands of their jobs. Empowering leadership seems to display a different pattern of relationships with job crafting behaviors: A study showed that empowering leadership, because it implies providing employees with strength to make their own decisions and to take additional responsibility, was positively related to the seeking of both job resources and challenging demands. However, it did not significantly relate to reducing the hindering demands of one's job (Thun \& Bakker, 2018).

In sum, results from prior research seem to lack consensus when it comes to the relationships between supportive forms of supervisory behaviors and the different facets of job crafting, which may be due to the conceptual differences underpinning these leadership behaviors. The present research therefore offers to contribute to shed light on these associations by taking into consideration a widely studied form of supportive supervisory behaviors, namely supervisor support, which was found to promote employees' attitudes and behaviors at work (Eisenberger \& Stinglhamber, 2011). Indeed, the leadership styles that were previously studied in relation to job crafting (e.g., autonomy support, engaging leadership, transformational leadership, and empowering leadership) may differ in terms of the specific characteristics of leaders' behaviors that they emphasize, which may explain their differentiated relationships with job crafting facets. Yet, all these forms of leadership share a common characteristic: They imply that supervisors support their subordinates. 
Supportive leaders, because they value their subordinates' contributions and ideas (Eisenberger \& Stinglhamber, 2011), may provide employees with opportunities to make their job more meaningful, thus allowing them to rely more importantly on strategies serving that end, such as seeking job resources and challenging job demands (Wrzesniewski \& Dutton, 2001). Moreover, supportive leaders care about their employees' well-being (Caesens, Gillet, Morin, Houle, \& Stinglhamber, 2020). As such, employees who perceive their supervisor as supportive may feel more free to reduce the hindering demands of their job as a way to preserve their well-being. In sum, because they foster mutual trust and openness and encourage initiative, supervisors may create a safe environment where their employees feel free to proactively change the characteristics of their job, without the fear of being blamed for it.

Hypothesis 4: Supervisor support positively relates to seeking job resources and challenging job demands, and to reducing hindering job demands.

\section{Method}

\section{Participants and Procedures}

Questionnaires were collected by research assistants in a convenience sample of 533 workers (220 men; 313 women) from various organizations (e.g., public hospitals, industries, sales, and services) located in France. The paper version of the questionnaire was made available by research assistants in several organizations, and the link to the online survey was sent via email to potential participants and posted on social media. Because of this data collection method, it was impossible to determine exactly how many people originally had access to the questionnaire and therefore to estimate a return rate.

The questionnaire came with a cover letter explaining the objectives of the study, and a consent form stressing that participation was anonymous and voluntary. Questionnaires required approximately 15 minutes to complete. All questionnaires were administered in 
French and instruments not already available in this language were adapted using a standardized back-translation procedure (van de Vijver \& Hambleton, 1996). Respondents were aged between 18 and 64 years $(M=34.05, S D=10.76)$, had an average organizational tenure of 8.02 years $(S D=8.20)$, and an average tenure in the current position of 4.79 years ( $S D=5.38$ ). In addition: (a) $74.8 \%$ of the participants worked full-time, and (b) $2.1 \%$ of the participants had no diploma, $12.9 \%$ completed vocational training, $24.8 \%$ completed high school, and $60.2 \%$ completed university.

\section{Measures}

Work engagement. Work engagement was assessed using the nine-item Utrecht Work Engagement Scale (Schaufeli et al., 2006) covering vigor (three items; $\alpha=.88$; e.g., "At my work, I feel bursting with energy"), dedication (three items; $\alpha=.91$; e.g., "I am enthusiastic about my job"), and absorption (three items; $\alpha=.85$; e.g., "I feel happy when I am working intensely"). Responses were provided on a scale ranging from 1 (never) to 7 (always).

Exhaustion. Exhaustion was assessed with the five-item subscale $(\alpha=.90$; e.g., "I feel emotionally drained by my work") from the Maslach Burnout Inventory-General Survey (Schaufeli et al., 1996). All items were rated on a scale ranging from 1 (strongly disagree) to 5 (strongly agree).

Perceived support. Perceived supervisor $(\alpha=.87$; e.g., "My supervisor cares about my general satisfaction at work") and colleague ( $\alpha=.83$; e.g., "My colleagues really care about my well-being") support were each assessed using an adaptation of the four items from Eisenberger, Huntington, Hutchison, and Sowa's (1986) Survey of Perceived Organizational Support. In accordance with previous studies, this adaptation was done by replacing “organization” by “supervisor" or "colleagues" (e.g., Caesens et al., 2020). All items were rated on a scale ranging from 1 (strongly disagree) to 7 (strongly agree).

Job crafting. Participants' levels of seeking resources (six items; $\alpha=.79$; e.g., “I ask 
others for feedback on my job performance"), seeking challenges (three items; $\alpha=.72$; e.g., "I ask for more tasks if I finish my work"), and reducing demands (four items; $\alpha=$.76; e.g., "I try to ensure that my work is emotionally less intense") were measured using thirteen items from Petrou et al. (2012), which were rated on a scale ranging from 1 (never) to 7 (always).

\section{Analyses}

In this study, all models were estimated using Mplus 8 (Muthén \& Muthén, 2017) robust Maximum Likelihood (MLR) estimator, which provides parameter estimates, standard errors, and goodness-of-fit that are robust to the non-normality of the response scales used in the present study (Finney \& DiStefano, 2013). As in the Gillet, Caesens, Morin, and Stinglhamber's (2019) study, confirmatory factor analyses (CFA), bifactor-CFA, exploratory structural equation modeling (ESEM), and bifactor-ESEM representations of responses to the work engagement measure were separately estimated following Morin et al.'s (Morin, Arens, \& Marsh, 2016; Morin, Arens, Tran, \& Caci, 2016; Morin, Boudrias et al., 2016, 2017) recommendations (see the online supplements for additional information). Participants' ratings on the other determinants of job crafting considered in this study (i.e., exhaustion, perceived supervisor support, and perceived colleague support) were represented according to a CFA model with three distinct but correlated factors. Similarly, employees' ratings of job crafting were represented according to a CFA model including three other correlated factors representing seeking resources, seeking challenges, and reducing demands.

\section{Results}

\section{Preliminary Analyses}

Before testing our hypotheses, we examined the measurement of the variables including in our study. The goodness-of-fit of the various measurement models is reported in Table 1 and details on these models are presented in the online supplements. As in the Gillet et al.'s (2019) study, the bifactor-ESEM solution was retained for further analyses. The CFA model 
including the other determinants of job crafting considered in the present study (exhaustion, perceived supervisor support, and perceived colleague support) was able to achieve an acceptable level of fit to the data. In contrast, the CFA job crafting model was not able to achieve an acceptable level of fit to the data. Therefore, following the procedure described in the online supplements, we then tested an ESEM job crafting model. This ESEM job crafting solution was retained for further analyses and factor scores (estimated in standardized units with $M=0$ and $S D=1$ ) from this preliminary model were used in the predictive analyses. This approach allowed us to maintain some degrees of control for measurement errors (Skrondal \& Laake, 2001) without encountering the various biases described by Koch, Holtmann, Bohn, and Eid (2018) for models including a construct represented by the way of a bifactor operationalization (i.e., work engagement). Parameter estimates (factor loadings, uniqueness, and composite reliability) for all measures are reported in Tables S1 to S3 of the online supplements.

\section{Test of Hypotheses}

A predictive model including all the variables assessed in the present study was then tested. This model included work engagement represented as a bifactor-ESEM solution (one global factor and three specific factors), exhaustion, perceived supervisor support, and perceived colleague support as a CFA solution, and factor scores for seeking resources, seeking challenges, and reducing demands. In addition, the three job crafting factors were specified as regressed on the work engagement factors (one global factor and three specific factors), perceived supervisor support, perceived colleague support, and exhaustion factors. This model was able to achieve an acceptable level of fit to the data. The predictive results are reported in Table 2 .

Hypothesis 1 was confirmed as global levels of work engagement significantly related to seeking job resources $(\beta=.462, p<.001)$ and to seeking challenging job demands $(\beta=.538$, 
$p<.001$ ), but did not significantly relate to reducing hindering job demands. Turning our attention to work engagement's dimensions, the vigor, dedication, and absorption specific factors did not hold significant associations with seeking job resources. Dedication was significantly associated with seeking challenging job demands $(\beta=-.124, p<.05)$, while vigor and absorption did not significantly relate to this job crafting behavior. Absorption was significantly associated with reducing hindering job demands $(\beta=.207, p<.01)$, but vigor and dedication did not significantly relate to this job crafting strategy. Contrastingly, our study was not able to provide support for Hypothesis 2 as exhaustion was not significantly associated with any job crafting behavior.

Hypothesis 3 was partially confirmed as perceived colleague support significantly related to seeking job resources $(\beta=.120, p<.05)$ but also with reducing hindering job demands $(\beta=$ $.144, p<.05)$, while it did not hold a significant association with seeking challenging job demands. Finally, perceived supervisor support was significantly associated with seeking job resources $(\beta=.176, p<.01)$, but did not significantly relate to seeking challenging job demands nor to reducing hindering job demands. Hypothesis 4 was thus only partially confirmed.

\section{Discussion}

The purpose of this study was to provide a wider understanding of the determinants of job crafting by jointly considering employee well- and ill-being (work engagement and exhaustion) and socio-environmental factors (supervisor and colleague support) as possible antecedents.

\section{Theoretical Implications}

\section{Employees' Psychological Health and Job Crafting}

This study offered one of the rare joint explorations of how well- and ill-being relate to job crafting (Hakanen et al., 2018), and as such offers a more balanced and complete 
apprehension of workers' psychological health (Keyes, 2005) and how it may condition their job crafting behaviors. Results showed well-being to be an important determinant of job crafting. Precisely, results provided support for Hypothesis 1 by showing global levels of work engagement to foster promotion-focused forms of job crafting (i.e., seeking resources and seeking challenges). These results are in line with Hobfoll's (2001) COR theory as they show that workers, when they feel resourceful (i.e., engaged), have a natural drive to obtain and foster their resources and thus create resource caravans (Hobfoll, 2011). Results also provide support for the JD-R model's proposition according to which job crafting stems from employees' well-being, as engaged employees are motivated to remain in this state of wellbeing, and thus more prone to engage in job crafting behaviors to create their own gain spiral of resources (Bakker \& Demerouti, 2017).

However, global levels of work engagement did not significantly relate to reducing demands, suggesting that engaged employees may be resourceful enough to not perceive job demands as a threat to their resources and thus not feel the need to protect from job demands by reducing them (Hobfoll, 2001). This result from a diversified sample of employees contrasts with those found by Hakanen et al. (2018) in a specific population of dentists, where authors found work engagement to relate significantly and negatively to reducing hindering demands. It should still be noted that, in Hakanen et al.'s (2018) study, this link between work engagement and prevention-focused job crafting, though significant, was much weaker than the ones between work engagement and promotion-focused forms of job crafting (Lichtenthaler \& Fischbach, 2019), which is in line with our results. Moreover, we confirm Tims et al.'s (2015) results, which also showed work engagement to promote job crafting seeking behaviors but not reducing demands. In sum, we corroborate the idea that work engagement is not significantly -or weakly- associated with prevention-focused forms of job crafting (Lichtenthaler \& Fischbach, 2019). 
Moreover, our study is, to the best of our knowledge, the first to explore how the different facets of work engagement relate to distinct job crafting strategies. Based on a B-ESEM representation of work engagement ratings, which expands recent research on the multidimensionality of this construct (Gillet et al., 2019; Perera et al., 2018), we thus provided initial evidence of how non-redundant estimates of vigor, dedication, and absorption relate to job crafting dimensions, over and above global levels of work engagement. Precisely, our results indicated that specific levels of dedication and absorption, unlike specific levels of vigor, explained unique variability respectively in seeking challenges and reducing demands, over and above that already explained by global levels of work engagement.

Specifically, once global levels of work engagement were taken into account, specific levels of dedication were associated with less seeking challenging demands, which may come as a surprise considering that dedication implies a sense of challenge, pride, significance, and enthusiasm (Schaufeli, Shimazu, Hakanen, Salanova, \& De Witte, 2019). Yet it may be that dedicated employees, in essence, already seek the right amount of challenge and may want to keep this level of optimal challenge in order to remain proud and enthusiastic about their work, as more challenge may make their jobs more strained and less significant. Indeed, research based on the Too-Much-of-a-Good-Thing effect, which "occurs when ordinarily beneficial antecedents reach inflection points after which their relations with desired outcomes cease to be linear and positive" (Pierce \& Aguinis, 2013, p. 316), has suggested that work engagement, beyond a certain point, may yield counterintuitive consequences (Caesens, Stinglhamber, \& Marmier, 2016; Shimazu, Schaufeli, Kubota, Watanabe, \& Kawakami, 2018). In sum, research suggests that when employees are excessively enthusiastic and challenged at work, they eventually lack the opportunity to recover and restore the resources they dedicated to work (Sonnentag, 2011), and may thus lack the resources to take on new challenges. 
Moreover, once global levels of work engagement were taken into account, specific levels of absorption were associated with more reducing hindering demands, which may be due to the fact that absorbed employees perceive job demands as an obstacle to their being fully concentrated and deeply captivated by their work (Schaufeli et al., 2019), so they try to reduce such demands. This result thus shows that a specific facet of work engagement may actually positively relate to prevention-focused forms of job crafting. This unexpected result may be due to the fact that absorption is thought to be less of a core dimension of work engagement than other facets, as it as does not refer to employees' being energized and rather resembles the calm state of flow (Salanova \& Schaufeli, 2008). Altogether, these results on the specific variance of job crafting that is associated with the dedication and absorption components seem to indicate that dedicated and absorbed employees want to foster and protect their resources (Hobfoll, 2001).

Though well-being in the form of work engagement appears to be an important source of job crafting behaviors, ill-being does not appear to significantly relate to job crafting. Precisely, our study was not able to confirm our second hypothesis according to which exhausted employees would try to preserve themselves from further resource loss (Hobfoll, 2001) by engaging in prevention-focused forms of job crafting (i.e., reducing hindering job demands). Though prior research found contrasting results between exhaustion and job crafting dimensions (Hakanen et al., 2018; Petrou et al., 2015), our research is, to the best of our knowledge, the first to show that exhaustion is not a relevant determinant of job crafting. These results may indicate that, just like well- and ill- being stem from different antecedents (i.e., job resources and demands; Bakker \& Demerouti, 2017), they also imply different consequences, with well-being (work engagement) relating to positive forms of proactive behaviors such as job crafting, while ill-being (exhaustion) may yield more negative forms of passive behaviors such as procrastination (Metin, Taris, \& Peeters, 2016). 


\section{Others' Support and Job Crafting}

Regarding the socio-environmental conditions that may foster job crafting, our results showed that perceived colleague support was associated with more seeking resources and more reducing demands but did not relate to seeking challenges, thus providing partial support for Hypothesis 3. Our results thus corroborate prior research (Audenaert et al., 2020; Kerksieck et al., 2019) by showing that when they have social resources (i.e., colleague support), employees are likely to seek more resources. Moreover, our study shows that colleague support may act as a safety net allowing employees to reduce the hindering demands of their job without fearing negative interpersonal consequences for their behaviors (Plomp, Tims, Khapova, Jansen, \& Bakker, 2019). Altogether, these results are consistent with COR theory (Hobfoll, 2001) as they show that when employees feel that they have relational resources (colleague support), they have a natural drive to protect these resources (reducing demands) and to obtain more resources (seeking resources) through job crafting behaviors. The non-significant association between colleague support and seeking challenging job demands may be due to the nature of social support provided by coworkers. Precisely, recent research has suggested that social support was not necessarily beneficial for their recipients (Gray et al., 2019). For instance, colleague support may imply interactions drawing workers' attention to negative aspects of their job (Beehr, Bowling, \& Bennett, 2010), thus dispiriting them and discouraging them from taking on new challenges.

Moreover, our study showed that perceived supervisor support was associated with more seeking resources but did not relate to seeking (challenging) or reducing (hindering) job demands. Hypothesis 4 was thus only partially supported. In other words, our study seems to indicate that perceived supervisor support only triggers resource-related job crafting strategies. In doing so our research corroborates prior research showing different forms of supervisory behaviors to be unrelated to reducing hindering demands, which may be due to 
the fact that supportive supervisors already regulate hindering demands in order to provide their subordinates with the best conditions to complete their job. Our results are also in line with those of Hetland et al. (2018) who showed transformational leadership to solely relate to seeking resources but not to seeking challenging demands.

Once again, this non-significant relationship between supervisor support and employees' seeking challenging job demands may be explained by the nature of social support provided by supervisors, which although ostensibly helpful, may not produce the intended effect. It could be that supervisors provide an unhelpful type of social support (i.e., an action taken by a supervisor that the subordinate believes was intended to benefit them but is perceived as unhelpful; Gray et al., 2019). Indeed, supportive supervisors care about their subordinates' well-being and value their contributions (Eisenberger \& Stinglhamber, 2011). Yet, they may not necessarily encourage employees and create the conditions for self-initiation (Slemp, Kern, Patrick, \& Ryan, 2018) or may not encourage learning and provide guidance to help subordinates take on new challenges (Rocchi, Pelletier, Cheung, Baxter, \& Beaudry, 2017). In other words, the construct of supervisor support may not cover all the important interpersonal behaviors that supervisors need to combine to encourage employees to seek challenging job demands.

In sum, it appears that supportive supervisors and colleagues, by fostering trust and openness, may create a safe environment where employees feel free to try new things, such as job crafting, without fearing making mistakes. Our study therefore adds up to the scarce research on the relational determinants of job crafting by providing a first joint exploration of colleague and supervisor support in relation to job crafting and showing them to be relevant levers to promote some job crafting strategies.

Finally, our study explored these relationships in a country where job crafting was rarely explored (e.g., Huyghebaert-Zouaghi et al., 2020) and in a large sample of workers from 
various occupations, thus extending prior research which mostly focused on specific cultures and occupations (Lichtenthaler \& Fischbach, 2019). Precisely, our research partly corroborated results from previous studies conducted in other countries and occupations and shed light on other results contrasting with prior research. In sum, our study indicates that job crafting displays differentiated patterns of associations with various antecedents, depending on the sample under study. In other words, the optimal conditions for job crafting to occur may, to some extent, be culture-specific.

\section{Limitations and Research Directions}

Even though it offers a joint consideration of well- and -ill being together with socioenvironmental factors that may trigger job crafting strategies, while relying on a bifactor representation of work engagement, this research presents some limitations. First, we relied on self-report measures, which may have been impacted by social desirability and self-report biases. Future research could use other-rated measures of the variables included in this study. For instance, employees' emotional exhaustion could be rated by their spouse, while work engagement could be rated by supervisors. Second, research could explore whether our results generalize to additional cultural, linguistic, or specific socio-economic groups. For instance, we relied on a sample of highly educated workers, one may thus wonder whether psychological health and colleague/supervisor support would hold the same relations with job crafting in a sample of less qualified workers. A similar question may hold as to whether the relational determinants we studied would relate to job crafting in a similar way in non-western cultural contexts, characterized by more collectivistic cultural practices (Bohnlein \& Baum, 2020). Third, in this research, we did not differentiate between the seeking of structural and social resources. Future research could look into how work engagement, as well as supervisor and colleague support, associate with these different forms of resources one can seek through job crafting. For instance, because colleague and supervisor support both constitute social 
resources, one can wonder whether employees who benefit from strong support from their colleagues/supervisors would be more likely to try to cultivate this type of resources by seeking social resources or whether they would be more inclined to seek resources of a different nature (i.e., structural). Fourth, future research would benefit from longitudinal designs allowing for a more precise investigation of the temporal effects of the determinants of job crafting. Finally, in this study we explored colleague support as a conceptual antecedent of job crafting. Yet, recent research has emphasized that colleague support toward job crafters could result from the latter's job crafting (Tims \& Parker, 2020). Future research could thus explore the reciprocal relations between colleague support and job crafting behaviors in order to deepen the understanding of the interpersonal implications of job crafting.

\section{Practical Implications}

This research emphasizes some practical implications for both organizations and researchers. Our study sheds light on possible triggers to promote some job crafting behaviors, in a context where many studies have pointed to individual differences and demographics (see Rudolph et al., 2017) as determinants of job crafting. Yet, organizations have little leverage to act on such factors. Our study points to work engagement, as well as supervisor and colleague support, as relevant determinants of different job crafting strategies, and thus give organizations some leeway for job crafting promotion. Indeed, organizations have a certain flexibility to create the conditions that may boost work engagement and consequent job crafting strategies, by creating resourceful work environments which may fuel a positive gain spiral for employees and organizations both (Bakker \& Demerouti, 2017). Our study also encourages organizations to create the conditions for colleague and supervisor support to develop as these relational assets form a safe space where certain job crafting strategies can occur. Based on the trickle-down effect proposed by Eisenberger and 
Stinglhamber (2011), organizations could start with developing organizational support, as perceived organizational support may convey a norm according to which everyone within the organization is expected to be supportive of others (Frear, Donsbach, Theilgard, \& Shanock, 2018) and spread in the form of supervisor and colleague support. Organizations could also offer supervisors and employees trainings on how to be supportive with others, as brief trainings of the sort proved to be efficient (Gonzalez-Morales, Kernan, Becker, \& Eisenberger, 2018).

Our results also have implications for scholars. By demonstrating that a bifactor ESEM representation of work engagement is superior to alternative solutions, our results suggest that it is fundamental to consider the possibility that the items used to assess work engagement (UWES-9) may tap into both a global component (global levels of work engagement) and into specific facets (specific levels of vigor, absorption, dedication). Failing to consider the multidimensionality underlying work engagement ratings may unduly lead researchers to observe comparable effects of these constructs' specific facets on related outcomes (Morin, Arens, \& Marsh, 2016). Yet, these comparable effects would merely reflect the underlying effect of the global construct and conceal the possible complementary effects of work engagement imbalance (i.e., the meaningful specificities remaining in each of the specific facets). Moreover, our results showing the superiority of bifactor ESEM representations of work engagement should raise awareness in researchers on the risk of ignoring cross-loadings (i.e., reliable associations between items and more than one factor). For instance, levels of vigor may influence responses to items designed to assess dedication or absorption. As such, not considering such cross-loadings may result in overrating the importance of work engagement's global factor (Asparouhov, Muthén, \& Morin, 2015). In sum, failing to consider the multidimensionality underlying work engagement ratings may lead to an inaccurate view of the reality under study and to erroneous recommendations for practice. 


\section{References}

Asparouhov, T., Muthén, B., \& Morin, A. J. S. (2015). Bayesian structural equation modeling with cross-loadings and residual covariances. Journal of Management, 41(6), 15611577.

Audenaert, M., George, B., Bauwens, R., Decuypere, A., Descamps, A. M., Muylaert, J., ... \& Decramer, A. (2020). Empowering leadership, social support, and job crafting in public organizations: A multilevel study. Public Personnel Management, 49(3), 367-392.

Bakker, A. B., \& Demerouti, E. (2017). Job demands-resources theory: taking stock and looking forward. Journal of Occupational Health Psychology, 22(3), 273-285

Baumeister, R. F., \& Leary, M. R. (1995). The need to belong: desire for interpersonal attachments as a fundamental human motivation. Psychological Bulletin, 117(3), 497529.

Beehr, T. A., Bowling, N. A., \& Bennett, M. M. (2010). Occupational stress and failures of social support: When helping hurts. Journal of Occupational Health Psychology, 15(1), 45-59.

Berg, J. M., Grant, A. M., \& Johnson, V. (2010). When callings are calling: Crafting work and leisure in pursuit of unanswered occupational callings. Organization Science, 21(5), 973-994.

Blau, P. M. (1964). Exchange and power in social life. New York, NY: Wiley.

Bohnlein, P., \& Baum, M. (2020). Does job crafting always lead to employee well-being and performance? Meta-analytical evidence on the oderating role of societal culture. The International Journal of Human Resource Management. Advance online publication. doi: $10.1080 / 09585192.2020 .1737177$ 
Caesens, G., Gillet, N., Morin, A. J. S., Houle, S. A., \& Stinglhamber, F. (2020). A PersonCentred Perspective on Social Support in the Workplace. Applied Psychology, 69(3), 686-714.

Caesens, G., Stinglhamber, F., \& Marmier, V. (2016). The curvilinear effect of work engagement on employees' turnover intentions. International Journal of Psychology, $51(2), 150-155$.

Eisenberger, R., \& Stinglhamber, F. (2011). Perceived organizational support: Fostering enthusiastic and productive employees. Washington, DC: APA Books.

Eisenberger, R., Stinglhamber, F., Vandenberghe, C., Sucharski, I. L., \& Rhoades, L. (2002). Perceived supervisor support: contributions to perceived organizational support and employee retention. Journal of Applied Psychology, 87(3), 565-573.

Finney, S. J., \& DiStefano, C. (2013). Nonnormal and categorical data in structural equation modeling. In G.R. Hancock \& R.O. Mueller (Eds.), Quantitative methods in education and the behavioral sciences: Issues, research, and teaching. Structural equation modeling: A second course (pp. 439-492). Charlotte, NC: IAP Information Age Publishing.

Frear, K. A., Donsbach, J., Theilgard, N., \& Shanock, L. R. (2018). Supported supervisors are more supportive, but why? A multilevel study of mechanisms and outcomes. Journal of Business and Psychology, 33(1), 55-69.

Gillet, N., Caesens, G., Morin, A. J. S., \& Stinglhamber, F. (2019). Complementary variableand person-centred approaches to the dimensionality of work engagement: A longitudinal investigation. European Journal of Work and Organizational Psychology, 28(2), 239-258. 
Gonzalez-Morales, M. G., Kernan, M. C., Becker, T. E., \& Eisenberger, R. (2018). Defeating abusive supervision: Training supervisors to support subordinates. Journal of Occupational Health Psychology, 23(2), 151-162.

Gray, C. E., Spector, P. E., Lacey, K. N., Young, B. G., Jacobsen, S. T., \& Taylor, M. R. (2019). Helping may be Harming: unintended negative consequences of providing social support. Work \& Stress. Advance online publication. doi: 10.1080/02678373.2019.1695294

Hakanen, J. J., Peeters, M. C., \& Schaufeli, W. B. (2018). Different types of employee wellbeing across time and their relationships with job crafting. Journal of Occupational Health Psychology, 23(2), 289-301.

Hetland, J., Hetland, H., Bakker, A. B., \& Demerouti, E. (2018). Daily transformational leadership and employee job crafting: The role of promotion focus. European Management Journal, 36(6), 746-756.

Hobfoll, S. E. (2001). The influence of culture, community, and the nested-self in the stress process: Advancing conservation of resources theory. Applied Psychology, 50(3), 337421.

Hobfoll, S. E. (2002). Social and psychological resources and adaptation. Review of General Psychology, 6(4), 307-324.

Hobfoll, S. E. (2011). Conservation of resource caravans and engaged settings. Journal of Occupational and Organizational Psychology, 84(1), 116-122.

Huyghebaert-Zouaghi, T., Morin, A. J. S., Forest, J., Fouquereau, E., \& Gillet, N. (2020). A longitudinal examination of nurses' need satisfaction profiles: A latent transition analysis. Current Psychology. Advance online publication. doi: 10.1007/s12144-02000972-1 
Kerksieck, P., Bauer, G. F., \& Brauchli, R. (2019). Personal and social resources at work: Reciprocal relations between crafting for social job resources, social support at work and psychological capital. Frontiers in Psychology, 10:2632.

Keyes, C. L. (2005). Mental illness and/or mental health? Investigating axioms of the complete state model of health. Journal of Consulting and Clinical Psychology, 73(3), $539-548$.

Koch, T., Holtmann, J., Bohn, J., \& Eid, M. (2018). Explaining general and specific factors in longitudinal, multimethod, and bifactor models: Some caveats and recommendations. Psychological Methods, 23(3), 505-523.

Lichtenthaler, P. W., \& Fischbach, A. (2019). A meta-analysis on promotion-and preventionfocused job crafting. European Journal of Work and Organizational Psychology, 28(1), $30-50$.

Mäkikangas, A., Bakker, A. B., \& Schaufeli, W. B. (2017). Antecedents of daily team job crafting. European Journal of Work and Organizational Psychology, 26(3), 421-433.

Metin, U. B., Taris, T. W., \& Peeters, M. C. (2016). Measuring procrastination at work and its associated workplace aspects. Personality and Individual Differences, 101, 254-263.

Morin, A. J. S., Arens, A. K., \& Marsh, H. W. (2016). A bifactor exploratory structural equation modeling framework for the identification of distinct sources of constructrelevant psychometric multidimensionality. Structural Equation Modeling, 23(1), 116139.

Morin, A. J. S., Arens, A. K., Tran, A., \& Caci, H. (2016). Exploring sources of constructrelevant multidimensionality in psychiatric measurement: A tutorial and illustration using the Composite Scale of Morningness. International Journal of Methods in Psychiatric Research, 25(4), 277-288. 
Morin, A. J. S., Boudrias, J. S., Marsh, H. W., Madore, I., \& Desrumaux, P. (2016). Further reflections on disentangling shape and level effects in person-centered analyses: An illustration exploring the dimensionality of psychological health. Structural Equation Modeling, 23(3), 438-454.

Morin, A. J. S., Boudrias, J. S., Marsh, H. W., McInerney, D. M., Dagenais-Desmarais, V., Madore, I., \& Litalien, D. (2017). Complementary variable-and person-centered approaches to the dimensionality of psychometric constructs: Application to psychological wellbeing at work. Journal of Business and Psychology, 32(4), 395-419.

Muthén, L. K., \& Muthén, B.O. (2017). Mplus: Statistical analysis with latent variables: User's guide (Version 8). Los Angeles, CA: Muthén \& Muthén.

Perera, H. N., Vosicka, L., Granziera, H., \& McIlveen, P. (2018). Towards an integrative perspective on the structure of teacher work engagement. Journal of Vocational Behavior, 108, 28-41.

Petrou, P., Demerouti, E., \& Schaufeli, W. B. (2015). Job crafting in changing organizations: Antecedents and implications for exhaustion and performance. Journal of Occupational Health Psychology, 20(4), 470-480.

Petrou, P., Demerouti, E., Peeters, M. C., Schaufeli, W. B., \& Hetland, J. (2012). Crafting a job on a daily basis: Contextual correlates and the link to work engagement. Journal of Organizational Behavior, 33(8), 1120-1141.

Pierce, J. R., \& Aguinis, H. (2013). The too-much-of-a-good-thing effect in management. Journal of Management, 39(2), 313-338.

Plomp, J., Tims, M., Khapova, S. N., Jansen, P. G., \& Bakker, A. B. (2019). Psychological safety, job crafting, and employability: A comparison between permanent and temporary workers. Frontiers in Psychology, 10:974 
Rocchi, M., Pelletier, L., Cheung, S., Baxter, D., \& Beaudry, S. (2017). Assessing needsupportive and need-thwarting interpersonal behaviours: The Interpersonal Behaviours Questionnaire (IBQ). Personality and Individual Differences, 104, 423-433.

Rudolph, C. W., Katz, I. M., Lavigne, K. N., \& Zacher, H. (2017). Job crafting: A metaanalysis of relationships with individual differences, job characteristics, and work outcomes. Journal of Vocational Behavior, 102, 112-138.

Salanova, M., \& Schaufeli, W. B. (2008). A cross-national study of work engagement as a mediator between job resources and proactive behaviour. The International Journal of Human Resource Management, 19(1), 116-131.

Schaufeli, W. B., Shimazu, A., Hakanen, J., Salanova, M., \& De Witte, H. (2019). An ultrashort measure for work engagement: The UWES-3 validation across five countries. European Journal of Psychological Assessment, 35(4), 577-591.

Schaufeli, W. B., Bakker, A. B., \& Salanova, M. (2006). The measurement of work engagement with a short questionnaire: A cross-national study. Educational and Psychological Measurement, 66(4), 701-716.

Schaufeli, W. B., Leiter, M. P., Maslach, C., \& Jackson, S. E. (1996). The MBI-general survey. In C. Maslach, S.E. Jackson, \& M.P. Leiter (Eds.), Maslach burnout inventory manual (3rd ed., pp. 19-26). Palo Alto, CA: Consulting Psychologists Press.

Schuler, B. A., Binnewies, C., \& Bürkner, P. C. (2019). The relationship between job crafting, work engagement, and performance: A meta-analysis. Advance online publication. doi: 10.31234/osf.io/xpf2v

Shimazu, A., Schaufeli, W. B., Kubota, K., Watanabe, K., \& Kawakami, N. (2018). Is too much work engagement detrimental? Linear or curvilinear effects on mental health and job performance. PloS one, 13(12), e0208684. 
Skrondal, A., \& Laake, P. (2001). Regression among factor scores. Psychometrika, 66(4), $563-575$.

Slemp, G. R., Kern, M. L., Patrick, K. J., \& Ryan, R. M. (2018). Leader autonomy support in the workplace: A meta-analytic review. Motivation and Emotion, 42(5), 706-724.

Slemp, G. R., Kern, M. L., \& Vella-Brodrick, D. A. (2015). Workplace well-being: The role of job crafting and autonomy support. Psychology of Well-being, 5(1), 7.

Sonnentag, S. (2011). Research on work engagement is well and alive. European Journal of Work and Organizational Psychology, 20(1), 29-38.

Thun, S., \& Bakker, A. B. (2018). Empowering leadership and job crafting: T he role of employee optimism. Stress and Health, 34(4), 573-581.

Tims, M., \& Bakker, A. B. (2010). Job crafting: Towards a new model of individual job redesign. SA Journal of Industrial Psychology, 36(2), 1-9.

Tims, M., Bakker, A. B., \& Derks, D. (2013). The impact of job crafting on job demands, job resources, and well-being. Journal of Occupational Health Psychology, 18(2), 230-240.

Tims, M., Bakker, A. B., \& Derks, D. (2015). Job crafting and job performance: A longitudinal study. European Journal of Work and Organizational Psychology, 24(6), 914-928.

Tims, M., \& Parker, S. K. (2020). How coworkers attribute, react to, and shape job crafting. Organizational Psychology Review, 10(1), 29-54.

Van de Vijver, F., \& Hambleton, R. K. (1996). Translating tests. European Psychologist, 1(2), 89-99.

Wrzesniewski, A., \& Dutton, J. E. (2001). Crafting a job: Revisioning employees as active crafters of their work. Academy of Management Review, 26(2), 179-201. 
Table 1

Goodness-of-Fit Statistics and Information Criteria for the Measurement Models

\begin{tabular}{|c|c|c|c|c|c|c|}
\hline Model & $\chi^{2}$ & $d f$ & CFI & TLI & RMSEA & RMSEA 90\% CI \\
\hline \multicolumn{7}{|l|}{ Work Engagement } \\
\hline CFA & $259.087 *$ & 27 & .888 & .850 & .127 & {$[.113 ; .141]$} \\
\hline Bifactor-CFA & $208.228 *$ & 21 & .910 & .845 & .129 & {$[.114 ; .146]$} \\
\hline ESEM & $37.214^{*}$ & 12 & .988 & .963 & .063 & {$[.041 ; .086]$} \\
\hline Bifactor-ESEM & 7.171 & 6 & .999 & .997 & .019 & {$[.000 ; .062]$} \\
\hline \multicolumn{7}{|l|}{ Other Predictors } \\
\hline CFA & $153.538 *$ & 56 & .965 & .951 & .057 & {$[.046 ; .068]$} \\
\hline \multicolumn{7}{|l|}{ Job Crafting } \\
\hline CFA & $197.639 *$ & 65 & 913 & .895 & .062 & {$[.052 ; .072]$} \\
\hline ESEM & $115.358^{*}$ & 42 & .952 & .910 & 057 & {$[.045 ; .070]$} \\
\hline Predictive Model & 404.177* & 212 & .972 & .960 & .041 & {$[.035 ; .047]$} \\
\hline
\end{tabular}

Note. $* p<.01 ; d f$ : Degrees of freedom; CFI: Comparative fit index; TLI: Tucker-Lewis index;

RMSEA: Root mean square error of approximation; CI: Confidence interval.

\section{Table 2}

Results for the Predictive Model

\begin{tabular}{lccc}
\hline & $\begin{array}{c}\text { Seeking } \\
\text { Resources }\end{array}$ & $\begin{array}{c}\text { Seeking } \\
\text { Challenges }\end{array}$ & $\begin{array}{c}\text { Reducing } \\
\text { Demands } \\
\beta\end{array}$ \\
Predictors & $\beta$ & $\beta$ & $\beta$ \\
\hline Work engagement Global Factor & $.462^{* * *}$ & $.538^{* * *}$ & -.179 \\
Vigor Specific Factor & .025 & .081 & .004 \\
Dedication Specific Factor & -.051 & $-.124^{*}$ & .146 \\
Absorption Specific Factor & .043 & .012 & $.207 * *$ \\
Perceived Supervisor Support & $.176^{* *}$ & .103 & .054 \\
Perceived Colleague Support & $.120^{*}$ & -.070 & $.144^{*}$ \\
Exhaustion & .078 & .143 & -.163 \\
\hline
\end{tabular}

Note. $* p<.05 ; * * p<.01 ; * * * p<.001$ 